\title{
INSERÇÃO DA QUESTÃO FILOSÓFICA NA HISTÓRIA *
}

\author{
Ubaldo Puppi **
}

TRANS/FORM/AÇAO/22

PUPPI,U. - Inserção da questão filosófica na história. Trans/Form/Ação, São Paulo, 3:65-79, 1980.

RESUMO: A filosofia, particularmente em fase crítica como a atual, se apresenta como questão. Mas, a questão atual da filosofia é simultaneamente a questão da tradição que produziu a filosofia. Questionada a partir do seu interior, a filosofia persevera, renovando-se; questionada a partir de fora, de uma posição cética, não só sua existência, mas toda a problemática dela decorrente, são recusadas. No entanto, na instância da ciência, pretensamente erigida em bastião do ceticismo, descobre-se a urgência daquilo mesmo que em seu nome é negado. A história da filosofia é o espaço onde ecoa e prolifera a questão da filosofia. Em seu contexto, por meio desta, a filosofia é sempre atual, transforma-se, pluraliza-se.

UNITERMOS : A questão da filosofia; tradição filosófica. História da filosofia. Preconceito. Hermenêutica. Totalidade diacrônica.

\section{1 - INTRODUÇÃO DA QUESTÃO}

A legitimidade do Tema proposto não deriva de pura opção, nem tampouco do acaso. Impõe-se como crise, pela própria tarefa filosófica, sob a forma de questão. Toda crise, com efeito, gera questões e, inversamente, estas para além de um certo limite denunciam crises profundas ainda que latentes e encobertas. A filosofia, que atravessa uma fase de desestabilização e de transição, de crise enfim, se apresenta a fortiori como questão. Questão sobre sua verdadeira identidade e sobre seu alcance para o homem e o mundo modernos, estes, também passando por processos profundos de transformação. E, de resto, sempre assim que a filosofia perdura e se mantém atual, que ela em suma é de novo compreendida e sua compreensão aprofundada.

Eis aí o início da formulação do tema: filosofia, o que é isso? Ao tentar responder, descobre-se que o processo de discussão já supõe uma determinada concepção da filosofia, conduzindo portanto a um círculo vicioso; depois de longo caminho, retorna-se ao ponto de partida. Se é a própria filosofia que está em crise,

* Texto parcialmente apresentado na IV Jornada de Filosofia e Teoria das Ciências Humanas, com o título de "O Auto-Questionamento da Filosofia".

${ }_{* *}$ Professor Titular junto ao Departamento de Filosofia da Faculdade de Educação,

Filosofia, Ciências Sociais e da Documentação da UNESP - Campus de Marília. 
PUPPI, U. - Inserção da questão filosófica na história. Trans/Form/Ação, São Paulo, 3:65-79, 1980.

resta todavia intacta a pergunta. A pergunta sobre a filosofia numa fase de filosofia em crise, não é uma crise da pergunta. Perguntar o que é a filosofia torna-se por redução a única questão, a questão fundamental à qual se reporta toda outra pergunta filosófica. Efetivamente, a pergunta filosófica sobre algo implica que a filosofia pode responder; se, porém, a pergunta incide sobre a própria filosofia, toda pergunta filosófica queda em suspenso. Sintetizo a gama inteira dessas perguntas na simples expressão "questão filosófica". Sem dúvida, a questão da filosofia reporta, mais fundamentalmente ainda, à filosofia da questão. Não é, porém, da filosofia da questão que se trata aqui, e que será objeto de outro estudo, trata-se da questão da filosofia. Se metodologicamente a questão da filosofia pode ser isolada da filosofia da questão, é pelo contrário por exigência de método que a questão da filosofia se articula com a questão da tradição filosófica. Colocar, com efeito, a questão da "questão filosófica" já é colocar a questão da "tradição filosófica", que também está em crise na crise da filosofia. A crise da filosofia é a crise não só da filosofia atual, mas de toda a tradição filosófica.

Assim, a questão da tradição filosófica compõe uma temática única com a questão da filosofia. A questão filosófica, é não só a filosofia em questão, mas simultaneamente a questão da tradição que produziu a filosofia ao ser produzida por ela. Se, pois, a questão filosófica mantém estreitos e necessários vínculos com a tradição filosófica, a questão da tradição filosófica se esclarece sempre de novo à luz da resposta atual à questão filosófica. Não fosse o risco de simplificar demasiadamente o conteúdo, o título do trabalho poderia ser "A questão filosófica hoje, e suas relações com a tradição filosófica".
Risco, no caso, seria entender tradição filosófica de modo tradicional, isto é, tomá-la em sentido vulgar e usual, não no sentido hermenêutico que o próprio contexto lhe confere.

Não se trata de atitude forjada e sem aval em uma prática, visando reinventar o que é a filosofia e o valor da tradição filosófica; nem tampouco da ambição de propor-lhes "nova concepção"; mas, o que quer que aconteça, de honestamente expor-se a uma problemática abscuramente perseguida, que começa a se definir objetivando-se, mas que só se realiza como processo. Visa, em síntese, reatar com a vida e a tradição filosóficas por meio da reativação da própria origem da filosofia, que é a questão filosófica. Foi na verdade a questão filosófica que historicamente deu origem à filosofia e the conferiu a sua especificidade (01). Evidentemente, o pensador préfilosófico não começou a se por a pergunta acerca do que ainda não existia, mas o surgimento da primeira pergunta filosófica, - uma pergunta filosófica, não a questão da filosofia, - já precontinha implicitamente a questão da filosofia. A partir de sua origem histórica, a questão da filosofia passou a ser, no sentido kierkegaardiano da palavra, a repetição do ato originário. Essa questão deve sofrer seu desdobramento lógico no espírito do filósofo, sem necessariamente vir expressa no discurso que ela desencadeia e que a ela responde, como pretendo mostrar em outro trabalho.

Acionar a questão filosófica é na verdade produzir discurso, mas o discurso que ela produz não se confunde com ela, nem a esgota. Resta de qualquer modo que o discurso filosófico, em cada uma das instâncias do seu devir, depende essencialmente de uma retomada radical a partir do próprio agente, sob pena de 
PUPPI, U. - Inserção da questão filosófica na história. Trans/Form/Ação, São Paulo, 3:65-79, 1980.

incorrer em mera reprodução, o que vale dizer numa transferência do critério de juízo a discursos alheios, antes enérgicos, na fonte, mas agora estagnados na imitação ortodoxa ou eclética. Definitivamente, a filosofia contrai um pacto de origem com o autor. Tanto mais que, rigorosamente falando, não há modelo nem método a serem seguidos em filosofia, nem é questão só de arbítrio. Ela é a busca e o registro de um encontro sempre único com a questão da verdade e a descoberta do conhecimento como manifestação do sentido no elemento de uma linguagem em simbiose com a tradição que a semantiza. Contudo nem por isso, por esse seu aspecto de valor e fruição contemplativos, se confunde com o conforto fácil na satisfação estacionária da ideologia própria erigida em lição de humanismo.

Essa vinculação do questionamento pessoal com uma tradição precisa ser bem compreendida, e no exercício filosófico raramente o é desde o início. Os modos de desentendê-la ou de desatendê-la são variados. Há exercícios para os quais a insistência no questionamento pessoal acarreta a crença em uma incompatibilidade com a tradição; outros, para os quais é a tradição filosófica que, desde que ela existe, pareceria dispensar o questionamento pessoal, por ocioso ou mesmo comprometedor e perigoso. A menos que c desentedimento seja proveniente de um clima hostil ou refratário tanto ao questionamento pessoal quanto à tradição à qual este se vincula.

A fixação em um desses desentendimentos já representa mutilação do munus philosophicum. A primeira mutilação consistindo em recuar a uma corrente de pensamento do passado, privilegiando-a e procurando inconsideradamente amoldá-la, por bem ou por mal, à contemporaneidade. Advirta-se que esse pri- vilegiamento de uma corrente de pensamento do passado nada tem a ver com o verdadeiro sentido da tradição, e que a tentativa pura e simples de amoldá-lo à contemporaneidade possui o condão de abafar o questionamento pessoal e, portanto, de eludir o problema da tradição. A segunda mutilação é a que induz a empalmar o passado, a minimizá-lo ou ignorá-lo. Deve-se observar que essa valorização unilateral do questionamento filosófico em detrimento da tradição, não só endossa tacitamente a postura ingênua que confunde privilegiamento do passado e tradição, como também desgarra o discurso filosófico de seu próprio quadro de referência; por isso mesmo, a adoção dessa postura se liga mais a modismos do que à sua legitimidade intrínseca.

A gravidade maior de uma e outra posturas reside menos no fato da mutilação do que na inconsciência de sua prática. O reconhecimento de um contexto assim desfigurado, dominado pela presença de oposições contrárias, não só falsas tomadas cada uma em separado, mas também incompatíveis entre si tomadas em conjunto, não é condição suficiente para o surgimento de um meio termo de conciliação, ou de um terceiro termo de superação. É até mais comumente plausível que, por si só, esse reconhecimento conclua antes a favor da inexequibilidade de uma saída. Inexequibilidade que redunda em descrença no valor da filosofia e induz ao ceticismo sobre a importância do questionamento e da tradição filosóficos. Basta então que esse ceticismo esteja comprometido com a ciência, a práxis, a técnica ou a burocracia, para nelas sepultar a filosofia, ainda que o epitáfio pretenda ser uma homenagem ao morto. Nesse caso, não deixaria de ser inquietante a persistência do questionamento filosófico na história do homem e da humanidade. 
PUPPI, U. - Inserção da questão filosófica na história. Trans/Form/Ação, São Paulo, $3: 65-79,1980$.

\section{2 - PARA ALÉM DA CIÊNCIA A QUESTÃO FILOSÓFICA}

\subsection{Os Fatos Humanos}

Dos três malogrados modos de vinculação da questão filosófica com a tradição, acima apontados, o último merece ser tratado em primeiro lugar. Se os dois restantes incorrem em falhas que comprometem ora um, ora outro dos termos inter-vinculados, mantêm-se em todo o caso sob o horizonte comum da filosofia, onde precisamente estão expostos à crítica pertinente e à contingência de re-orientação, ao passo que o terceiro modo recusa, juntamente com a filosofia, os próprios termos da proposta. Antes de tudo convém, pois, isolá-lo e concentrar o exame em torno do objeto e da prática da ciência, para tentar surpreender o que possa transgredir e transcender seus limites e sua competência, erigindo-se em problema filosófico.

Entre as ciências, serão tomadas como referência as ciências do homem. Obviamente, lidam elas com os fatos humanos: afirmação correta que, no entanto, oculta um paradoxo, aliás inevitável. Os fatos humanos são por natureza significativos, verdade reconhecida pela própria comunidade científica. Com efeito: "todo ato humano tem um sentido" assegura Freud (5, p. 45); para Max Weber, o agir social é um comportamento significante, isto é, observa Habermas, "um comportamento orientado em um sentido compreendido subjetivamente, e por isso mesmo também motivado, o qual só pode ser adequadamente captado com referência aos objetivos e aos valores pelos quais o sujeito agente se orienta" $(08$, p. 83$)$; Granger adverte peremptoriamente que "o ato humano comporta uma face significativa" (07, p. 133); nem mesmo autores ligados ao neo-positivismo como $\mathrm{E}$.
Nagel o negam (11, p. 433 ss.). Não obstante, não é enquanto significativos que as ciências humanas, na medida em que são rigorosa e estritamente ciências, lidam com seus objetos. Pelo contrário, elas neutralizam essa característica, formalizando-a, ou a reduzem a variáveis de comportamento observável. Nem sempre nos damos conta do que é assim neutralizado e reduzido, e que por essa razão deve ser sempre enfatizado.

Considerar o ato humano como significante, é tomá-lo em sua especificidade humana, que permanece existencialmente intocada e inalterada na vigência mesma da prática teórica que a neutraliza ou que a reduz para conhecê-la e ao conhecê-la. Ela possui e conserva indelével e imprescriptivelmente a marca característica do agente, que torna o ato humano sempre, de algum modo, orientado, o modo pelo qual se constituem a animação e a racionalidade do sujeito. A essa orientação, Husserl, - depois de Von Brentano, e este depois de Tomás de Aquino, denomina intencionalidade, como à subjetividade, que é a central da intencionalidade, chama de consciência (09).

Por seu ser constitutivamente intencional, a consciência é radicalmente e sempre "consciência de algo" (10, p.28) e, decorrentemente, auto-consciência. A intencionalidade própria dos atos humanos significa precisamente que, enquanto consciência, o sujeito agente acumula dupla função: função trans-itiva, ou de transcendência, e função reflexiva, ou de imanência. Assim, se a significação dos atos humanos reside em sua intencionalidade, sem esta aqueles permanecem num estágio infra-humano, por inadimplência de sua compreensão, ou por terem sido neutralizados e reduzidos a esse nível por elisão. 
O que dá sentido portanto a um ato humano como tal é a intenção, ou intencionalidade, que o guia e orienta, e por meio do qual ele é compreendido. Ação e intenção são aí realmente inseparáveis, mas, para efeito de conhecimento, precisam ser distintamente concebidas e identificadas. Elas se vinculam, uma em relação à outra, exatamente como o signo e o significado na linguagem. As ações exprimem e representam intenções, do mesmo modo que os símbolos linguísticos os seus significados. A semelhança dos signos linguísticos, que não podem ser compreendidos e interpretados sem o conteúdo simbolizado, as ações humanas jamais serão adequadamente compreendidas e interpretadas sem seu conteúdo intencional. A relação, porém, entre ação e intenção, como a relação entre significante e significado não é empírica, mas inteligível; não é psíquica, mas lógica. Não se trata meramente dos interesses próprios de um indivíduo, trata-se substancialmente de características universais do ser do homem. Aqui a observação espontânea do sensível cede lugar à compreensão elementar, e a observação controlada é substituída por um procedimento hermenêutico, posto que a esse nível o desvelamento da determinação intencional se dá em conexão com símbolos. Eis por que a experiência está vinculada aí, não com a percepção sensível, mas com a comunicação linguística.

É o que o último Husserl já começava a vislumbrar nas "Meditações Cartesianas" e na "Crise das Ciências...", ao concluir que não apenas o mundo se constitui, recebe seu sentido de mundo, em uma consciência, em um sujeito, mas que o próprio sujeito é suscetível de constituição, que ele se deve portanto conquistar pela reflexão sobre a vida irrefletida. De modo interligado, distingue ele duas sortes de intencionalidade: a intencionalidade operante, de cunho espontâneo e vivido, e a intencionalidade temática, convergindo com o que denominamos precisamente procedimento hermenêutico.

A intencionalidade operante é a intencionalidade não explicitada como tal $\mathrm{e}$ que se ignora, pela qual no entanto é objetivado, quer dizer, ao mesmo tempo constituído e tematizado, o "mundo" da atitude natural, no qual esta aliena o "sujeito" agente. Domínio da consciência ainda alienada, a intencionalidade operante se oferece como um fecundo lugar de encontro entre Husserl e Hegel, como também entre Husserl e Freud, estes últimos, aliás, responsáveis pela mais desenvolvida problemática da intencionalidade, por ambos haurida na fonte brentaniana. Com esta diferença, porém: enquanto um a concebia em sua essência universal, ora como operante, ora como tematizada, outro a concebia como reprimida e mascarada por intenções adventícias. Todas essas aproximações são mais condizentes com o último Husserl do que as interpretações que recebeu do existencialismo de Sartre, cujos desenvolvimentos do nãotético comportam, se não um retrocesso, pelo menos um estágio estacionário em relação à intencionalidade operante, traduzido por insuperados compromissos com o psicologismo.

Note-se ainda que o sulco da intencionalidade operante é exatamente o lugar epistemológico para a análise da ideologia. Esta tem sido encarada de modo habitual sob o ângulo de visualização da sociologia do conhecimento. Sob essa abordagem, ela é tratada, ora genericamente, como um sistema mais ou menos coerente de "idéias" próprias a um grupo social, a uma época, e que traduzem uma cumplicidade histórica, ora restritivamente, como falsa consciência que, na quali- 
PUPPI, U. - Inserção da questão filosófica na história. Trans/Form/Ação, São Paulo, $3: 65-79,1980$.

dade de superestrutura, cauciona a divisão da sociedade em classes e as relações de dominação. Um difundido dogmatismo ideológico desta concepção restrita da ideologia, - "hipócrita" no sentido de Merleau Ponty e que pretende fundar-se em Marx, - inclui a filosofia no rol da ideologia. Basta, como refutação, mostrar onde reside a "hipocrisia", óbvia no caso, desde que explicitada. E preciso reconhecer então que, se a sociologia do conhecimento apropriou-se do vocábulo para designar a área que este, segundo ela, cobre, não merece contemplação quando extrapola. Daí a entrada em cena de duas outras linhas semânticas possíveis. A primeira, abstraindo do sentido imposto pela sociologia do conhecimento, deixa-se guiar pelo étimo; ideologia seria o discurso das idéias, na acepção favorável de Destutt de Tracy, que a propôs para substituir "psicologia", mas que poderia ser aproximadamente a de epistemologia ou de teoria do conhecimento, como em Maine de Biran, sem deixar de mencionar a acepção pejorativamente idealista introduzida por Napoleão Bonaparte. A segunda linha de interpretação endossa a imposição de sentido da sociologia do conhecimento, mas situando-a em seu devido lugar no quadro do saber. A ideologia aparece então como vinculada à intencionalidade operante, e associada a outras espécies de conhecimento espontâneo. Sob esse prisma, seria ela teoricamente uma modalidade de conhecimento ingênuo, - manipulado politicamente, ou não, - que se contrapõe não só à ciência e à filosofia, mas ainda a outras variantes do conhecimento espontâneo, e que na prática se mescla e se insinua no âmbito daquelas.

O "mundo" e o "sujeito" constituídos e tematizados no sulco da intencionalidade operante são o postulado de realidade da atitude natural, implicada até na prática científica. Atitude que se conserva atada à consciência alienada, ainda que, a pretexto de critério crítico, se venha hipostaziar "mundo" e "sujeito" como inacessíveis coisas-em-si, ou inversamente coarctá-los à mera positividade fática, quando não a proclamar sua morte ontológica. Nesse labirinto, o homem poderia ser levado a extraviar-se sem o fio de Ariadne da filosofia. Esta, questiona o "mundo" e o "sujeito" constituídos, ocupando-se sob forma de atitude reflexiva do próprio processo de constituição. A atitude reflexiva, contemporânea à instauração da crise do conhecimento alienado, torna viável a compreensão sem véus do sentido essencial das categorias de mundo e de sujeito, como também das categorias daí decorrentes.

\subsection{A Ciência dos Fatos Humanos}

Se o fato humano, tomado na instância de sua existência, é por natureza significante, na instância da ciência ele é objeto abstrato. É o que Granger quer fazer entender quando à "face significativa do ato humano" ele acrescenta "uma face obejtiva" (07, p. 133). Na linguagem aqui adotada, seria mais correto e mais preciso falar, respectivamente, em sua especificidade propriamente humana, como vimos fazendo, e em sua especificidade científica. No segundo caso, o fato "humano" não passa de um objeto abstrato, tal como é concebido e construído pela visada formal e redutora da ciência. Seu contexto, advirta-se, não é mais a instância da existência, mas a estrutura abstrata da ciência. A simples colocação da questão nesses termos já é filosófica, como filosófica é a questão da correlação entre existência e estrutura da ciência.

Nesta altura, convém alertar para a leitura gramatical da expressão "ciências humanas". O adjetivo é do mesmo nível 
PUPPI, U. - Inserção da questão filosófica na história. Trans/Form/Ação, São Paulo, 3:65-79, 1980.

de pertinência unívoca que o nome qualificado, isto é, "humana" significa o objeto abstrato e formal da "ciência". Com essa advertência prévia, lembremos que as ciências humanas se distribuem em duas espécies processualmente distintas: ciências do tipo clássico, "galiléico" ou energético, tão rigorosamente ciências como a física, que serve aqui de paradigma, e que procedem por subsunção lógica; ciências do tipo semiótico, "saussuriano", ou informacional, ciências do mesmo gênero que as energéticas, mas cujo protótipo continua sendo a fonologia, isto é, um código informacional detectado como sistema de oposições (*). Ambas as espécies organizam-se como modelos formais que, além de permanecerem fragmentários e lacunares na tentativa de estruturação dos fatos humanos, neles sacrificam o significado em sua inteligibilidade real, a intencionalidade. Esse sacrifício da intencionalidacie ocorre por conseguinte até inlesmo no domínio das ciências áo tipo semiótico.

Dada a natureza significativa do fato humano, ele recebe o tratamento de um signo, diferenciando-se ora preferentemente como significante, ora preferentemente como significado. Daí a dupla modalidade de consideração, que o expõe à ambiguidade. Considerado como signo, mas prescindindo do significado real, o fato humano é assumido como significante que reporta a outros fatos humanos assumidos nas mesmas condições de prescindência, e com eles se integra em uma estrutura na qual adquirem um significado adventício, constituído logicamente pelo conjunto das leis formais imanentes.

Nessas semióticas, o significado do fato humano, prescindido que foi, passa para um plano inteiramente irrelevante, conservando a função de uma relação originária para a identificação do significante $(* *)$. A preservação ou recuperação do significado real se dá de modo "compreensionista", mediante procedimento hermenêutico, em dois planos: o plano dos sistemas científicos e o plano da ontologia.

O pressuposto teórico para o prosseguimento da análise é o da dupla origem do significado dos atos humanos, seu duplo modo de ser compreendido. Serão ambos designados, de agora em diante, respectivamente de intenção e intencionalidade, não sem alguma arbitrariedade $(* * *)$. A intenção revelará sempre um sentido imposto, o ato de imposição e a sua resultante sendo toma-

* É preciso esclarecer que semiótica é assumida aqui como qualificando a classe da ciência dos signos, por oposição à semiótica como teoria geral dos signos. Como teoria geral dos signos, a semiótica "nada mais é do que "a doutrina da natureza essencial e das variedades fundamentais da 'semeiosis' possível". É a semiótica desenvolvida por Peirce. Como classe da ciência dos signos, porém, a "semiologia [a semiótica] estuda a vida dos signos no seio da vida social" (Saussure), isto é, estuda os signos culturais no interior dos grupos humanos. Nesse nível se enquadram Barthes, Levi Strauss, etc.

* A análise dos semiólogos é um pouco diferente. Eles se referem, no caso, ao signo de origem (simultaneamente significante e significado) como o significante da estrutura ou do sistema de nível superior. Evito de propósito essa formulação, pela simples razão que nem sempre o significado de origem é captado antes de ser prescindido, o que me permite atribuir a essa altura da problemática um maior grau de generalidade, como convém ao presente encaminhamento.

* * Não são considerados, por não constituirem propriamente atos humanos, as afecções físicas ou mentais, signos naturais que interessam à semiologia médica em função da diagnose. 
PUPPI, U. - Inserção da questão filosófica na história. Trans/Form/Ação, São Paulo, 3:65-79, 1980.

dos, por metonímia, um pelo outro. A imposição do sentido deriva do poder inventivo de que dispõe o homem para criar signos, investindo um significado não percebido, - um logos, um telos, um conatus afetivo ou estético, - em um significante perceptível, seja este um ato humano não linguístico, o som articulado ou não, o símbolo gráfico, um objeto cultural, uma relação social, etc. Esse leque sígnico propicia o surgimento de sistemas compreendentes de caráter psicológico, sociológico, ou estético. A diferença da intenção, a intencionalidade é diretamente motivada pelo objeto atuando por atração, tanto in praesentia como in absentia, sobre a fonte geradora dos atos humanos, que daí emergem naturalmente investidos nessa intencionalidade. Ela não adere ao seu suporte por imposição de vim ato distinto dele. A única interferência possível a seu respeito se resume em explicitá-la. Sua marca distintiva é não depender de intenções individuais ou socializadas para existir, sendo-lhes anterior e uma condição de possibilidade. Se na intenção o significante é sempre patente e o significado latente, na intencionalidade nem o significante é sempre patente, sendo então objeto de experiência hermenêutica.

Esse pressuposto teórico permite situar, face às ciências de estrita observância, os sistemas científicos compreendentes e a ontologia, o que será feito por partes.

Entre o tratamento estritamente científico e o tratamento filosófico, permanece livre todo um vasto espaço que é preenchido por tentativas e ensaios teóricos de cunho científico, mas mais flexíveis e elásticos. Por vários motivos: ou porque guiados pelo zelo de não ocultar a especificidade significativa do fato humano, sem assumir a postura filosófica, ou porque, ora a amplitude do objeto, ora a sua perspectiva de abordagem não permitiram ainda, ou não permitirão nunca, um grau suficiente de rigor e de fechamento científico. Nesse caso se encontram tanto aproximações teóricas de caráter energético, para a análise do objeto empírico, como sistemas significantes de caráter semiótico, para a análise de contextos informacionais e quejandos. "Procedimentos de fronteira" como lembra Strasser (13), acionando "um discurso mixto, ambíguo mesmo" $(12$, p. 75$)$, segundo Ricoeur, mesclam-se aí critérios metodologicamente científicos com interpretações compreensionistas de ordem conjectural, mas fundadas em razões, ou mesmo de natureza filosófica. Interpretação compreensionista mantida sob o controle da ciência, cujos limites em todo caso se tornam mais indecisos e ampliados.

O que porém a filosofia autonomamente desvela ou deixa ser no ato humano é, na verdade, a sua marca ontológica, que antes de tudo não é senão o seu significado essencial, a intencionalidade. Operante no ato humano como presença vivida, ela já é como tal virtualmente tematizável, o que requer a intervenção do $\operatorname{logos}$. A tematização não dispensa, pois, a intervenção de um logos imanente vinculado estreitamente à linguagem, por cuja mediação se põe a descoberto. Estranha cumplicidade, sujeita às mais variadas explicações mas sempre à espreita do filósofo, não somente, em termos tradicionais desde Heráclito e Parmênides, entre o ser e o logos, entre o ser e o ser pensado, como também entre o logos e a linguagem, numa problemática que vem desde os sofistas gregos, o "Cálicles" de Platão, o "Da Interpretação" de Aristóteles, os estóicos. O logos, estranhamente conivente com o ser, revela-se assim como a razão de ser da linguagem que o mostra, enquanto a lin- 
guagem se mostra como a estância de infindas e variadas moradas que abrigam o logos. O logos do ser do ato humano não pode portanto ser plenamente captado sem ser dito. Quando Descartes diz "penso, logo existo", a afirmação da existência do sujeito pensante não resulta, para ele, de uma simples análise formal da linguagem, ou de mera subsunção lógica do "existo" a partir do "penso", mas da experiência vivida do ato cogitante, o logos ao ser mostrado, na e pela linguagem, o seu sentido, ou antes, um dos seus sentidos.

Constata-se, pois, que por via dos sistemas compreensionistas o significado força passagem para além da ciência, cujas fronteiras permeiam a filosofia, e que por via da ciência formal ele aparece como um resíduo irredutível, que apela diretamente para a filosofia. Daí se conclui obviamente que o tratamento adequado dos fatos humanos só se torna possível em uma prática de largo espectro, que se exerça não só no quadro estrito da objetividade científica, mas ainda na moldura mais abrangente e reveladora dos significados. Estes interessam à filosofia e se propõem como questão eminentemente filosófica. Desse modo, longe de absorver ou de invalidar o questionamento filosófico, como pretende preconceituosamente o positivismo, é a própria análise da prática científica que naturalmente conduz a aberturas filosóficas. Evidentemente, essas aberturas, para adquirir toda a sua força, precisam ser surpreendidas e desenvolvidas em sua esfera própria. Esta é toda a tradição filosófica.

\subsection{Atos de Conhecimento}

Se todas as classes de fatos humanos são significantes, uma delas é conhecente, e como tal não pode deixar de ser levada em conta. Que certos atos humanos se- jam conhecentes, significa comumente que são ora objeto, ora sujeito de conhecimento. Isso não quer dizer tão-somente que, se como objeto são os produtos da ciência, como sujeito sejam simetricamente o seu correlato produtor. Para além e aquém da ciência, as coisas são bem mais complexas do que parecem à sua luz. Em verdade, $o$ ato conhecente, enquanto sujeito do conhecimento, nunca é apenas sujeito. Em sua constitução imanente, ele já possui ao mesmo tempo uma polaridade subjetiva e uma polaridade objetiva: noese e noema, para recorrer a Husserl. E nessa distinção e simultaneidade que, de um lado, ele se manifesta à nível da filosofia, entenda-se mediante um novo ato de conhecimento produzido por reflexão; e que, de outro lado, ele se compõe como prática produtora do conhecimento.

E por essa peculiaridade única do ato conhecente que toda prática filosófica se desenvolve segundo um complexo jogo de movimentos, constitutivos uns, reflexivos outros, e reflexivos porque antes constitutivos. A descoberta remonta a Aristóteles (03 e 04), ressalvando aqui a liberdade das expressões, que não se atêm à sua letra: a orientação imediata do conhecimento racional se efetua na vecção noemática, coincidente grosso mado com o movimento primeiro da produção do discurso, pelo qual na instância da inocência primitiva se constitui o mundo da atitude natural e espontânea; só então, pelo efeito de um choque de retorno do discurso sobre si mesmo, o conhecimento se detem reflexivamente sobre o polo noético e sobre a vecção noética, e é quando se dá não só a experiência vivida de um "eu penso, eu sou", mas também a apercepção do "eu penso" como estrutura noético-noemática.

Pela mesma peculiaridade é que se sustenta a vinculação do processo cogni- 
PUPPI, U. - Inserção da questão filosófica na história. Trans/Form/Ação, São Paulo, 3:65-79, 1980.

tivo, através do noético, com a existência situada, e concomitantemente, através do noemático, com uma gramática geradora do discurso. Pelo vínculo com a existência e com as linguagens, o conhecimento é irrecusavelmente um acontecimento pessoal localizado em uma história e em uma cultura, com elas comprometido, e apto portanto, desde que exposto a uma leitura equipada e sutil, a denunciar também as relações existenciais e sociais que o determinam e sobredeterminam.

Inversamente, a detecção dessas relações por sua vez denunciarão conhecimentos. Efetivamente, na medida em que a prática existencial e a prática social dependem de constelações de valores, e na medida em que estes envolvem referências teleológicas a fundamentos, o correto questionamento filosófico contribui superlativamente para uma sanatio in radice. Pois, como garante $\mathrm{o}$ adágio "arcaico" (no duplo sentido) lembrado por Cajetanus, que cito de memória: "sicut in bivio, parvus error in princípio, maius erit in fine".

\section{3 - O REFERENCIAL DA HISTORIA DA FILOSOFIA}

Reafirmada a necessidade da questão filosófica pela discussão em contexto por meio do qual se pretendeu negar sua validade, é preciso agora relacioná-la com seu contexto de origem, formação e fomento. Estabelecem-se assim os dois polos indissociáveis da pesquisa, que condicionam a possibilidade mesma da continuidade da filosofia e de sua vigência aqui e agora. De um lado, a necessidade de um efetivo questionamento; de outro lado, o referencial da tradição no qual se insere. $\mathrm{Na}$ existência vicissitudinária do homem, surgem sem dúvida questões de cunho ideológico, cuja solução já está inscrita desde sempre em um horizonte inquestionado e apriorístico de interpretação. Não é o que se dá com o questionamento filosófico, cujo foro de discussão coincide com a tradição filosófica. Mas, ao invés de já estar aí pura e simplesmente inscrita a resposta ao questionamento pessoal, é todo um filão da tradição, senão a tradição toda inteira, que é por ele simultaneamente reproblematizada e atualizada. Ao ser reproblematizada, a tradição não só serve de teste, mas também de questionamento à questão que a questiona. O progresso é dialético, e por ele a filosofia se atualiza.

E claro que ao tentar responder à questão filosófica em seu estado emergente, possuimos um horizonte limitado de compreensão, constituído por nossos preconceitos atuais. Esclareço de passagem que assumo aqui a palavra preconceito, não no sentido pejorativo que lhe conferiu a Aufklärung, mas no sentido de pré-compreensão, imediatamente sugerido pelos elementos verbais; melhor seria dizer pré-juízo, não fosse em português a ambiguidade daí decorrente. Começamos pois a responder, e a nos responder, a partir de um horizonte preconcebido de compreensão. Se essa pre-compreensão não é entendida em sentido pejorativo, tampouco o é em sentido privilegiado. Vale o que vale, isto é, como uma instância para além de cujos limites é presentemente impossível ver.

Chegamos aqui a um ponto crítico. Antes de tudo, é preciso afastar o erro que consistiria em crer que esse horizonte atual é determinado e delimitado por um conjunto imutável de "pre-conceitos" (opiniões e apreciações) e que o passado se destaca sobre ele como um fundo transato e inerte (06, p. 284 ss). Essa é a visão e a prática do simplismo fixista. $\mathrm{Na}$ verdade, a atualidade do horizonte está em constante formação, e esta é desenca- 
PUPPI, U. - Inserção da questão filosófica na história. Trans/Form/Ação, São Paulo, $3: 65-79,1980$.

deada quando, por efeito da questão filosófica, os pre-conceitos são submetidos à prova. Como porém submetê-los à prova, questão e preconceitos, se não referindo-os à história da filosofia? A história da filosofia não é o depósito de respostas feitas para questões perenes renováveis sempre do mesmo modo, ou o repositório da crítica antecipada a nossos preconceitos, mas se constitui no medium objetivo de uma discussão que reinicia toda uma gênese. E dessa discussão que releva o genuíno encontro com o passado e a compreensão, - diria, melhor, a re-instauração, - de filões de tradição. $\mathrm{O}$ horizonte presente se torna, portanto, mediante a questão filosófica, um foco de tensões dialéticas, feito de reativação crítica do passado e de inovação histórica, isto é, de tradição e progresso.

Desse modo, o passado, ou vem integrar filões de tradição renovada e o progresso do pensamento atual, ou, depois de ter cumprido sua missão, é deixado em recesso. $\mathrm{O}$ que não quer dizer que o que permanece à margem desses filóes, no decorrido da filosofia, seja necessariamente pregresso: existe algo assim como caracteres recessivos no horizonte do presente.* Contudo sob outros pontos de vista, - só para mencioná-los: o da historiografia e o da eficiência histórica, - todas as manifestações filosóficas do passado, mesmo aquelas em recesso ou sob a forma de erro e abortamentos, podem ser significativas. São versões diferentes: a da questão filosófica, que conduz a filões de tradição sempre em tensão dialética; a da historiografia, que conduz a uma visão renovável do passado, mas sempre tópica e cronøgráfica. Diversas são também as funções: a da questão filosófica, com vistas a constituir, de novo, a filosofia e a tradição filosófica; a da historiografia, com vistas a identificar filosofias e tradições constituídas.

Resumindo, construimos o seguinte quadro heurístico. A questão filosófica nos reporta aos "pre-conceitos"; ao submetê-los à prova, penetramos obrigatoriamente na história da filosofia. Na história da filosofia, enquanto relacionada explicitamente com nossa questão filosófica, discernimos: aquilo que passa a constituir filões de tradição dialetizada, e como tal presentificada; aquilo que permanece simplesmente ausente, em recesso; aquilo que é relegado a contextos históricos superados, pregressos; aquilo que não sendo pregresso, nem integrante de um filão de tradição presentificada, e tampouco ausente e em recesso por caducidade, está no horizonte da filosofia atual como "presença" recessiva *. De outra ordem que os problemas assim formulados, embora por vezes muito próxima e até mesmo indistinta deles enquanto se constitui em seu fundo comum, é aqui apenas mencionada a historiografia, não visada diretamente.

(*) Sartre, no ocaso da existência, em recente entrevista a "Le Nouvel Observateur"

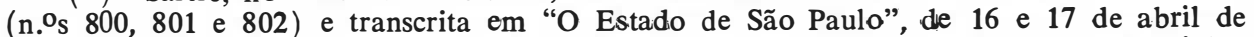
1980, ilustra bem quase todos os avatares da tradição: "O futuro desmentirá muitas de minhas afirmações. Espero que algumas sejam conservadas. De qualquer modo, há um movimento lento da história em direção a uma tomada de consciência do homem pelo homem. E nesse dado momento, tudo o que foi feito no passado ganhará seu lugar, ganhará seu valor... Tem-se que acreditar no progresso. Talvez seja esta uma de minhas derradeiras ingenuidades... A noção de fracasso não tem fundamento profundo para mim neste momento [teve]. Por outro lado, é a esperança, - enquanto relação entre o homem e seu objetivo (fim), relação que existe mesmo se o objetivo não é atingido, - que agora está mais presente em meus pensamentos" [antes estava ausente ou em "presença" recessiva]. (12, p. 26) 
PUPPI, U. - Inserção da questão filosófica na história. Trans/Form/Ação, São Paulo, 3:65-79, 1980.

\section{4 - A TRADIÇÃO FILOSÓFICA SEMPRE DE NOVO EM QUESTÃO}

Nesse quadro, a tradição ocupa o lugar e tem o valor de uma questão afim à questão filosófica. Por isso mesmo ampliando o que a respeito ficou dito mais acima, é preciso determinar a acepção em que a palavra é aqui assumida, o que será feito a partir dos sentidos que lhe foram efetivamente atribuídos, com maior, menor, ou sem nenhuma propriedade. A tradição, com efeito, foi entendida de dois modos gerais, um estático e outro dinâmico. No primeiro caso, não passaria ela de acúmulo sucessivo e automático de sistemas filosóficos, compondo o que seria então a "história da filosofia". Assim como, nessa ótica, a história se reduziria ao museu imaginário das memórias, a história da filosofia se reduziria à biblioteca que justapusesse lado a lado, em devida e boa ordem, as obras dos filósofos do passado, aos quais se iriam incorporando os contemporâneos. Existiria entre eles apenas relações cronológicas, parentescos e heterogeneidade. Visada conservadora da história e da filosofia, essa, resultante de uma tomada mecanicista e inspiradora de um didatismo simplório.

No segundo caso, são vários os submodos dinâmicos de conceber e de constituir a tradição, nem todos ou nem sempre válidos: há um critério causal; um critério dialético; um critério hermenêutico. O critério causal varia de acordo com o ponto de chegada ou com o ponto de partida: vis a fronte ou vis a tergo. A primeira variante, a vis a fronte, é exemplarmente ilustrada pela interpretação de Aristóteles sobre o pensamento dos filósofos que o antecederam, no seu entender etapas frustas e fragmentárias de um processo evolutivo que culminaria na sua própria filosofia, concebida como sendo o arcabouço essencial, e uma vez por todas, da filosofia mesma. Desse modo, todos os precursores estariam convergindo, é claro que sem o saberem, para o aristotelismo, como a um ponto de chegada; enquanto ele - em virtude de sua verdade identificada com "a verdade eterna de todas as pesquisas presentes e passadas" (2) - coincidiria em suas linhas mestras com o objetivo final da filosofia. A tradição nessa ótica, seria a história de seus antecedentes, nada mais.

A segunda variante do critério causal da tradição se encontra no tratamento não só privilegiado, mas mesmo dogmatizante, dado ao "Mestre" por toda uma família de epígonos, cuja doutrina ao ser produzida já preconteria a virtude e os princípios de solução para "resolver todos os problemas futuros", como de Aristóteles e Tomás de Aquino imaginavam aristotélico-tomistas; de Hegel, hegelianos; de Marx, marxistas; e mesmo de Comte, positivistas. De acordo com essa concepção, a tradição seria uma incessante vis a tergo a partir sempre do mesmo ponto, o "Mestre" insuspeito. Dotados de dinamismo, na mesma proporção em que privilegiam os pontos de chegada ou de partida, os critérios causais da tradição rejeitam no entanto o pluralismo. Os privilégios reivindicados para si são recusados às outras filosofias e tradições, diante das quais se comportam de modo exclusivista e imperialista, como sentinelas acadêmicas. Sorte extremada dessa modalidade causal, as injunções da ortodoxia marxista ombreiam neste particular com o tradicionalismo exacerbado ao estilo de De Bonald, de Maistre, Gustavo Corção.

O critério dialético da tradição é por excelência o hegeliano. Não entra em linha de conta neste estudo a dialética marxista, por não ser nem conter os de- 
PUPPI, U. - Inserção da questão filosófica na história. Trans/Form/Ação, São Paulo, 3:65-79, 1980.

senvolvimentos de uma teoria específica da tradição filosófica. A dialética hegeliana representa um critério sui generis de "vis a fronte", mas a atuação teleológica é exercida, não pela resultante exclusivista e imperialista de uma filosofia entre outras, mas pelo fato de ser ela pensada como a expressão da totalidade para a qual se encaminharam as filosofias do passado, expressões por sua vez de meros momentos ou etapas de um processo único do conceito. Nesse particular há, não se pode negar, certa semelhança entre Hegel e Aristóteles, que passa despercebida sob diferenças por demais flagrantes. $\mathrm{O}$ processo evolutivo da filosofia, para Aristóteles, era linear, e a diversidade nada mais seria do que a soma das variações ou desvios. Para $\mathrm{Hegel}$, esse processo é dialético, uma dialética entendida à sua maneira diferente das de Platão, Aristóteles e, mais tarde, de Marx, ao passo que a diversidade e pluralidade das filosofias seriam a decorrência complexa de vários fatores: finitude da história, lugar da manifestação da filosofia; riqueza multiforme da filosofia, que transborda as possibilidades do indivíduo e do momento histórico; processo gradualista da auto-revelação do espírito, a partir do qual e para o qual a filosofia se ex-põe (tese), se contra-põe (antítese), se dialetiza. A tradição, nessa monumental concepção, coincide com o movimento mesmo da manifestação da filosofia no concreto da história, mas movimento desenhado como esquema abstrato das suas necessárias contradições e constantes superações, tudo isso como condição transitória para a auto-manifestação final e total do Espírito. A consumação da filosofia seria a autoconsciência, construída na história, do homem-Deus.
Enfim, o critério hermenêutico $(*)$ da tradição, que é a concepção aqui adotada e que começou a ser esboçada mais acima, é aquela que me parece estar em melhores condições para responder ao tema e ao problema propostos. Consiste no processo de refundição, - senão sempre de refundação, - da tradição antecedente, por meio da questão filosófica. Preparando esse processo, há um duplo movimento de abrangências, de direções opostas e que se encontram em cada inflexão de uma mesma tradição. De um lado, a abrangência da tradição que precede uma nova questão filosófica, mas que já a precontem como possibilidade latente; de outro lado, a abrangência da questão filosófica que, ao se inserir na tradição precedente, a recolhe em seu horizonte. Mas, ao ser recolhida, seu campo de abrangência se funde com o do novo horizonte instaurado pela questão filosófica, o que supõe toda uma refundição, — se não refundação — da tradição. Pode-se, assim, falar da eficiência da tradição como síntese, - em cada um de seus momentos de inflexão, - da abrangência precursora da tradição antecedente e da abrangência renovadora da questão filosófica, a eficiência nada mais sendo de cada vez que o efeito conseqüente da refundição. Vivemos todos sob o influxo - reconhecido, ignorado ou negado, da tradição antecedente enquanto esta não sofre as consequiências de um questionamento que venhamos inaugurar, ou que nos venha afetar.

E por meio deste que se dá a passagem como um salto qualitativo, que longe de suprimir a tradição nela opera a mutação que reitera, em novas condições históricas, a sua própria essência e a possibilidade mesma de sua existência,

* Tomo hermenêutica na acepção que a modernidade lhe conferiu desde Schleiermacher e sucessivamente retomada por Dilthey, Heidegger, Gadamer, Ricoeur. 
PUPPI, U - Inserção da questão filosófica na história. Trans/Form/Ação, São Paulo, 3:65-79, 1980.

isto é, de sua perseverança. A tradição reiterada passa por mutações, transforma-se para perseverar; persevera evoluindo: ela se propõe então ao filósofo como a "sua" filogênese, e, ao ser assim assumida, ela se incorpora, transformada, à sua ontogênese.

\section{5 - A FILOSOFIA COMO TOTALIDADE DIACRÔNICA}

Eis como, a partir do seu próprio questionamento, a filosofia inova no tempo e para o seu tempo, renovando a tradição. Desde então, e nessa perspectiva, entre a nova visão filosófica e a inflexão da tradição dela decorrente, há, melhor do que fusão de abrangências ou refundição (refundação) da tradição, a formação de um horizonte único. E horizonte que tanto estende seus limites para o inédito e o prospectivo, como os recua para as profundezas da história. Horizonte filosófico único, porém, não deve ser confundido com unicidade da filosofia. Pois, é só e precisamente enquanto reativa e reavalia uma tradição, - cujo resultado merece aqui o nome de tradição reciclada, - que a nova visão filosófica constitui um horizonte único. Unico, mas compatível com a alteridade de outras tradições recicladas, anteriores ou concorrentes. A marca característica das tradições concorrentes reside na alteridade, ao passo que a cacaracterística das tradições concorrentes consiste em uma apropriação seletiva da história da filosofia. Por isso, se na perspectiva do cotejo e da emulação das alteridades predominam os conflitos de interpretação, as descontinuidades e as rupturas, na perspectiva da apropriação descortina-se a totalidade de um horizonte único.

A posse de um tal horizonte filosófico é um feliz resultado, antes raro, não mais raro porém do que a própria filosofia. Bem ou mal sucedida, menos ou mais bem, em crise de nascimento e de crescimento ou em processo abortivo, toda genuína tentativa filosófica passa pela experiência de uma relação de tensões entre a questão filosófica e a tradição antecedente. Na medida em que o tratamento dessa experiência é uma tarefa hermenêutica, esta não procura dissimular aquelas tensões sob as aparências de uma assimilação falaz, mas em desdobrá-las em pleno conhecimeno de causa.

Eis por que o momento problemático dessa hermenêutica implica necessariamente o reconhecimento de uma tradição prévia e antecedente, distinta da questão filosófica. Resulta daí, juntamente com a tarefa metodológica, o desconforto de uma consciência que se descobre dividida. A questão filosófica com efeito, consciente na origem, não produz eco senão na tradição precedente em que se insere, a qual de início se oferece à consciência como sua própria alteridade. É só quando a atitude hermenêutica bem sucedida se consuma, reunindo os dois polos antes destacados um do outro, que a consciência se reconcilia com ela mesma na unidade do mesmo horizonte filosófico recém-conquistado. Num ato assim acabado de compreensão é que se efetua a refundição, - ou refundação, — da tradição, sempre de novo e ao mesmo tempo superada e constituída. Uma verdadeira Aufhebung, essencialmente distinta da hegeliana e tipicamente hermenêutica. 
PUPPI, U. - Inserção da questão filosófica na história. Trans/Form/Ação, São Paulo, $3: 65-79,1980$.

TRANS/FORM/AÇÃO/22

PUPPI U. - Insertion of the philosophical question in history. Trans/Form/Ação, São Paulo, $3: 65-79,1980$.

SUMMARY: Philosophy, especially in a critical phase such as the present one, poses itself as a question. But the current question of philosophy is at the same time the question of the tradition that produced philosophy. Being questioned from withim, philosophy perseveres, renewes itself; questioned from the outside, from a skeptical position, not only its existence but also all its problems are rejected. Nevertheless on the level of science, which has supposedly been turned into a supporter of skepticism, one can find the urgency of the very same thing that is denied in its name. The history of philosophy is the place where the question of philosophy echoes and proliferates. In this context, and through its question, philosophy is always actual, it changes and pluralizes itself.

UNITERMS: The question of philosophy; philosophical tradition; history of philosophy; preconceptions; hermeneutics; diachronic totality.

\section{REFERENCIAS BIBLIOGRÁFICAS}

1. ARISTÓTELES, Metafísica. I, 2, $982 \mathrm{~b}$. 12.

2. Metafísica, Z, 1, 1028b 2.

3. Da alma, 429b, 5-9.

4. Ética nicomáquea. L. 9, cap.9.9.

5. FREUD, S. Introduction à la psycanalyse. Paris, Payot, 1961.

6. GADAMER, H. G. Wahrheit und methode. 3. ed. Tubingen, Mohr, 1973.

7. GRANGER, G.G. Philosophie du style. Paris, Armand Colin, 1968.
8. HABERMAS, J. Logica delle scienze sociali. Bologna, Il Mulino, 1970.

9. HUSSERL, E. Idées directrices pour une phénoménologie. 3. ed. Paris, Gallimard, 1950 passim.

10. Meditations cartésiennes. Paris, J. Vrin, 1969. V. 2.

11. NAGEL, E. The structure of science. New York, Harcourt, Brace \& World, 1961.

12. RICOEUR, P. De l'interpretation. Paris, Seuil, 1965.

13. STRASSER, S. Phénoménologie et sciences del'homme. Paris, B. Nauwelaerts, 1967. 